\title{
Proper orthogonal decomposition of ice velocity identifies drivers of flow variability at Sermeq Kujalleq (Jakobshavn Isbræ)
}

\author{
David W. Ashmore ${ }^{1}$, Douglas W. F. Mair ${ }^{1}$, Jonathan E. Higham ${ }^{1}$, Stephen Brough ${ }^{1}$, James M. Lea ${ }^{1}$, Isabel \\ 5 J. Nias ${ }^{1}$ \\ 1 - School of Environmental Sciences, University of Liverpool, Liverpool, L69 7ZT, UK. \\ Correspondence to: David W. Ashmore (ashmore@liverpool.ac.uk)
}

\begin{abstract}
The increasing volume and spatio-temporal resolution of satellite-derived ice velocity data has created new exploratory opportunities for the quantitative analysis of glacier dynamics. One potential technique, Proper Orthogonal Decomposition (POD), also known as Empirical Orthogonal Functions, has proven to be a powerful and flexible technique for revealing coherent structures in a wide variety of environmental flows. In this study we investigate the applicability of POD to an openly available TanDEM-X/TerraSAR-X derived ice velocity dataset from Sermeq Kujalleq (Jakobshavn Isbræ), Greenland. We find three dominant modes with annual periodicity that we argue are explained by glaciological processes.

15 Mode 1 is interpreted as relating to the stress-reconfiguration at the glacier terminus, known to be an important control on the glacier's dynamics. Modes 2 and 3 together relate to the development of the spatially heterogenous glacier hydrological system and are primarily driven by the pressurisation and efficiency of the subglacial hydrological system. During the melt season, variations in the velocity shown in Modes 2 and 3 are explained by the drainage of nearby supraglacial melt ponds, as identified with a Google Earth Engine MODIS dynamic thresholding technique. By isolating statistical structures within velocity

20 datasets, and through their comparison to glaciological theory and complementary datasets POD indicates which glaciological processes are responsible for the changing bulk velocity signal, as observed from space. With the proliferation of optical and radar derived velocity products (e.g. MEaSUREs/ESA CCI/PROMICE) we suggest POD, and potentially other modal decomposition techniques, will become increasingly useful in future studies of ice dynamics.
\end{abstract}

\section{Introduction}

25 The surface flow of glaciers is one of the most important measurements to assess the health of the cryosphere: critical to understand its mass balance and changing dynamics. It is an emergent property resulting from the complex interaction of numerous processes occurring on a variety of spatial and temporal scales. Prising apart the influence of the physical processes responsible for ice dynamic patterns has been a key aim in glaciology for decades and remains challenging for researchers. Technological advances and a growing appreciation of the need to resolve a wider range of glacier behaviour has led to satellite- 
https://doi.org/10.5194/tc-2021-184

Preprint. Discussion started: 12 July 2021

(c) Author(s) 2021. CC BY 4.0 License.

30 derived ice velocity images being acquired with increasingly regularity (Joughin et al., 2020a; Vijay et al., 2019; Lemos et al., 2018; Fahnestock et al., 2016), which, in turn, has allowed for the development of new analytical techniques and treatments of datasets (Riel et al., 2021; Greene et al., 2020).

One potential technique, Proper Orthogonal Decomposition (POD), also known as Empirical Orthogonal Functions (EOFs)

35 within meteorology and oceanography, has proven to be a powerful and flexible technique for revealing coherent structures in a wide variety of environmental flows. POD may have value in glaciology because it exactly describes a series of snapshots from a flow field with the product of ranked spatially orthogonal eigenfunctions, or "modes" of spatial weighting, and onedimensional "temporal" coefficients (eigenvectors). Importantly, in many cases the variance of the flow field is well described by just a few dominant orthogonal modes which, in theory, relate to distinct flow features. In this paper we explore the

40 applicability of this eigen-decomposition technique to a series of colocated satellite-derived ice velocity images for the first time. We use openly available ice velocity datasets and focus on the exceptionally well-sampled trunk of a major marineterminating glacier in West Greenland.

Greenlandic marine-terminating ("tidewater") glaciers are an intriguing test area for our analysis because they account for the majority of the ice sheet's contribution to global sea level rise (Mouginot et al., 2019), and anticipating their future behaviour is critical to improving our understanding of the health of the ice sheet (Choi et al., 2021; Catania et al., 2019). However, understanding the spatiotemporal dynamics of marine-terminating glaciers remains challenging; in part due to the competing and potentially interrelated atmospheric, geological, oceanographic, and glaciological factors affecting glacier geometry, flow and frontal ablation (e.g. Fahrner et al., 2021; King et al., 2020; Slater et al., 2019; Brough et al., 2019, Bevan et al., 2019;

50 Felikson et al., 2017; Straneo et al., 2010; Holland et al., 2008). In addition to the widespread, averaged multi-year trend of terminus retreat, the seasonal velocity patterns of these glaciers are often classified as being dominated by one of three types (Vijay et al., 2019; Moon et al., 2014), each relating to a specific dominant mechanism (e.g. Howat et al., 2010): (1) systems that are dominated by frontal stress-reconfigurations, and summer velocity is strongly linked to terminus position; (2) systems where the supply of meltwater to the ice-bed interface increases subglacial water pressure and enhances basal motion, and peak velocity occurs close to peak melt; and (3) where the subglacial drainage system adapts to the influx of subglacial water and develops from an inefficient, high-pressure, low-transit-time drainage system to an efficient, channelised system, and velocity tends to decrease throughout the melt season. This exemplifies the challenge of separating the relative importance of different flow mechanisms and forcings from the observed bulk signal: usually examined as points on a centreline or averaged over a region of interest.

60

Through the analysis presented in this paper we find that distinct spatial and seasonal patterns of ice velocity exist within the ice velocity dataset. We interpret the most dominant mode as being primarily due to glacier stress reconfiguration due to variations of frontal ablation. We then hypothesise that the smaller, subtler second modal signal is due to glacier hydrological 
https://doi.org/10.5194/tc-2021-184

Preprint. Discussion started: 12 July 2021

(c) Author(s) 2021. CC BY 4.0 License.

(c) (i)

forcing. By analysing timeseries of nearby supraglacial melt ponds, several published glaciological and environmental datasets, and errors associated with the input data we build a case for this interpretation and, therefore, the broader applicability of POD to ice velocity datasets.

\section{Data and Methods}

\subsection{Proper Orthogonal Decomposition}

POD is based on the decomposition of a geophysical field into a series of ranked eigenvectors and eigenfunctions that each partially explain the dataset variance, analogous to principal component analysis. The technique was originally derived to identify coherent structures, i.e. zones in which velocity fluctuations are correlated, in turbulent flow (Lumley, 1967). More recently, however, the ability of a POD to extract spatial pictures of regions of coherence has resulted in successes in relatable fields, e.g., fluvial hydrodynamics (Higham, 2017), granular rheology (Higham, 2020) and solar flare magnetohydrodynamics (Albidah, 2020).

The principle of a POD is that a series of snapshots of a centred (i.e. temporal mean removed) flow field can be exactly reconstructed by the product of spatially orthogonal eigenfunctions or "modes" of spatial weighting by their eigenvalues, and one-dimensional "temporal" coefficients (eigenvectors). A POD places no restriction on the temporal coefficients, such that these can be periodic, aperiodic, and with amplitudes which vary over time. Typically, in a fully converged dataset, a large proportion of the variance of the flow field can be explained by a few dominant modes. The orthogonal nature of each mode, by definition, means that independent forcing mechanisms on glacier motion should be identifiable by examining each mode individually. For a more detailed discussion readers are directed to several detailed reviews of POD and related techniques: Weiss (2019), Jolliffe \& Cadima (2016), Navarra \& Simoncini (2010).

85 Previously, POD has been applied to a variety of polar science problems (Datta et al., 2019; Bian et al., 2019; Mernild et al., 2017; Nield et al, 2012). In ice dynamic studies, however, the technique has been underutilised. To our knowledge its only published application to a time series of ice-surface velocity is by Mair et al. (2002) who decomposed measurements of ice velocity from a network of survey stakes on Haut Glacier d'Arolla during the 1995 melt season. Their analysis clearly indicated that although variations in the local driving stress dominated spatial variation in surface velocity, hydrologically-induced flow patterns were identified that defined the declining spatial extent of enhanced basal sliding in response to meltwater inputs as the subglacial drainage system's hydraulic efficiency evolved. In particular, they found that Mode 2 corresponded to the known location of an incipient subglacial drainage channel. The timing of a change in sign of the coefficient of this mode corresponded to the timing of a switch from inefficient, distributed drainage to efficient, channelised drainage, as deduced from results of multiple dye tracing experiments (following Nienow et al, 1998). Mode 2 was therefore interpreted to represent the changing basal sliding response to meltwater inputs to an evolving subglacial drainage system, switching from a high pressure, high 
https://doi.org/10.5194/tc-2021-184

Preprint. Discussion started: 12 July 2021

(c) Author(s) 2021. CC BY 4.0 License.

(c) (i)

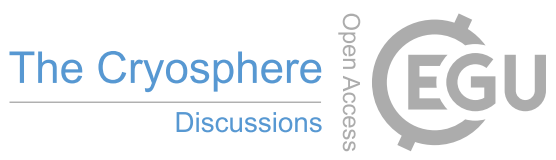

basal sliding response, to a low pressure, low sliding response. This early work provides a strong scientific motivation to explore the applicability of POD to modern, high-resolution satellite derived ice velocity datasets.

To determine the POD modes we calculate the eigenvectors and eigenvalues using an economy singular value decomposition

100 (SVD) (i.e. only solving T eigenvectors). We create a collection of column vectors $\mathbf{X}(\mathrm{n}, \mathrm{t})$ by column vectorising each of the individual $\mathrm{i} \times \mathrm{j}$ image snapshots where $\mathrm{n}=1,2, \ldots \mathrm{N}=\mathrm{ij}$ and $\mathrm{t}=1,2 \ldots \mathrm{T}$ are the number of equally spaced time-ordered snapshots. The SVD of the matrix $\mathbf{X}$ is given by:

$\mathbf{X}=\mathbf{U S V}^{*}$,

where,

$105 \mathbf{X}^{*} \mathbf{X}=\mathbf{V}\left(\mathbf{S}^{*} \mathbf{S}\right) \mathbf{V}^{*}$

$\mathbf{X X}^{*}=\mathbf{U}\left(\mathbf{S S}^{*}\right) \mathbf{U}^{*}$,

and

$\mathbf{U}^{*} \mathbf{U}=\mathbf{V}^{*} \mathbf{V}=\mathbf{I}$

where $*$ is a conjugate transpose and $\mathbf{I}$ is the identity matrix. From this decomposition $\mathbf{U} \in \mathbb{R}^{\mathrm{N} \times \mathrm{T}}$ relates to the orthogonal

110 spatial modes, each of $\mathbf{V} \in \mathbb{R}^{\mathrm{T} \times \mathrm{T}}$ (the eigenvectors) relate to the temporal evolution of the spatial modes, and both the spatial modes and temporal coefficients are ordered by the ordered eigenvalues contained by the diagonal of $\mathbf{S} \in \mathbb{R}^{\mathrm{T} \times \mathrm{T}}$. We further use these eigenvalues to describe the relative importance of each mode:

$S(\%)=100 \frac{\operatorname{diag}(\mathbf{S})}{\sum_{i=1}^{N} \gamma}$.

If we now transform each column of $\mathbf{U}$ back to image coordinates; these can be interpreted as the spatial patterns of

115 uncorrelated weighting which partially explain the geophysical field. We provide a visual representation of POD of a series of flow snap shots in Figure 1 and outline in Section 2.2.2 how POD is applied in this study to ice velocity data. 


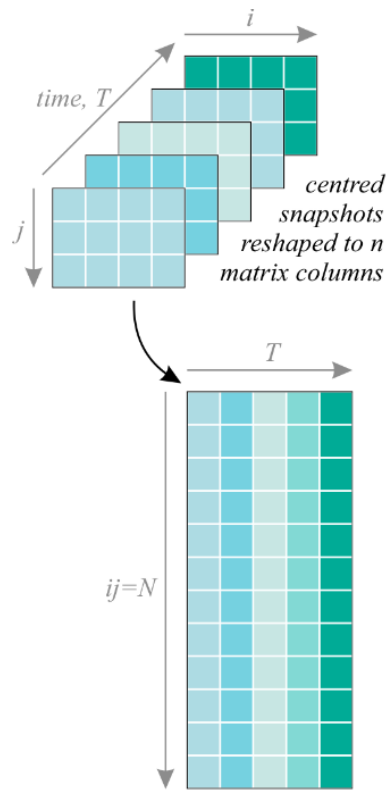

$\mathbf{X}$

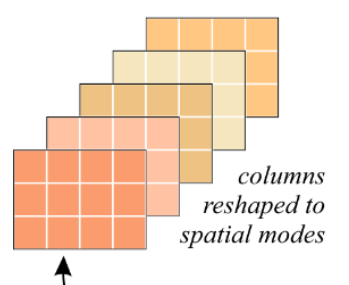

Proper orthogonal decomposition through economy-sized matrix singular value decomposition

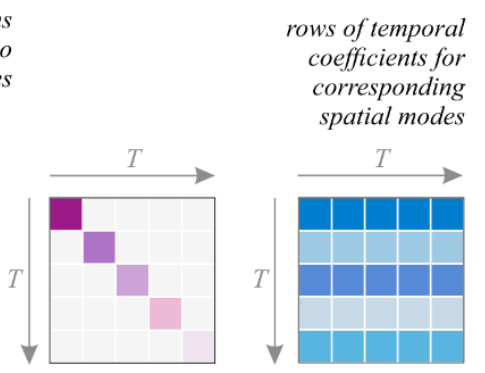

diagonal matrix of ranked values describing relative importance of modes

$\mathbf{S}$
$\mathbf{V}^{*}$

Figure 1: Schematic summarising the application and outputs of POD to a series of flow snapshots.

\subsection{Application}

\subsubsection{Study area and ice velocity data}

For this exploratory study, the selection of a study site and the availability of ice velocity data are interlinked. The study area must be dynamic, show seasonal variability and its velocity be well-sampled. With these criteria we selected Sermeq Kujalleq in West Greenland, also known as Jakobshavn Isbræ. Herein, we refer to this glacier with the initialism "SK-JI" to distinguish it from other Greenlandic glaciers with the same official name. SK-JI is covered by the "W69.10N" sub-region of the “MEaSUREs Greenland Ice Velocity: Selected Glacier Site Velocity Map Version 3” archive (Joughin et al., 2020a, Joughin et al., 2020b; Joughin et al., 2010). The primary data for this study are colocated ice-surface velocity magnitude rasters from this sub-region. The dataset has a nominal 100m $x y$-resolution, is derived from SAR imagery from 2008-2019, and hosted by the National Snow and Ice Data Center.

The ice velocity of this MEaSUREs sub-region is frequently measured with small image-pair separations and is therefore likely to capture the most complete range of glacier behaviour possible. Error associated with each pixel is approximately $\pm 10-20$ $\mathrm{m} \mathrm{a}^{-1}$ but may be subject to geolocation errors up to $100 \mathrm{~m}$, as outlined by Joughin et al. (2020a). We assign each velocity 
https://doi.org/10.5194/tc-2021-184

Preprint. Discussion started: 12 July 2021

(c) Author(s) 2021. CC BY 4.0 License.

(c) (i)

135 image the centre date from the image pairs used to derive it and record the image pair separation. In total 562 velocity magnitude images, and corresponding error maps, with centre-dates from 17-Jun-2008 to 20-Dec-2019 were accessed.

From this dataset we select spatial and temporal limits in which the applicability of POD can be best assessed. Spatially, this selection is driven by data coverage as expressed on a pixel-by-pixel basis as a percentage of those 562 velocity images which

140 contain a measurement. Temporally, this selection is driven by our requirement to identify a multi-year period where fluctuations in velocity are primarily annual and no, or very little, multi-year trend is observed and stationarity of the dataset is approached. We therefore select an exceptionally well sampled region of the SK-JI trunk (Figure 2) and an analysis period of summer 2012 (01-June) to end of winter 2016 (01-March). The inter-annual velocity variability of SK-JI is strongly related to its terminus position (Lemos et al., 2018; Bondzio et al., 2017) and this period corresponds to a time of relatively stable

145 frontal position with only a minor multi-year slowdown, whose rate increases markedly after 2016 (Lemos et al. 2018). Our study area contrasts to previous studies which have investigated the velocity of SK-JI with high temporal resolution at the near-terminus (Cassotto et al., 2015; Sundal et al., 2013). 232 velocity images are available covering the study period and area, 229 of which have an image-pair separation of 11 days; two (centre dates: 7-Aug-2013; 9-June-2015) have a separation of 22 days; and one (centre date: 1-Aug-2013) 33 days. The median difference between velocity image centre-dates is 5 days, the $15025^{\text {th }}$ percentile 1 day and $75^{\text {th }}$ percentile 10 days. 
(a)

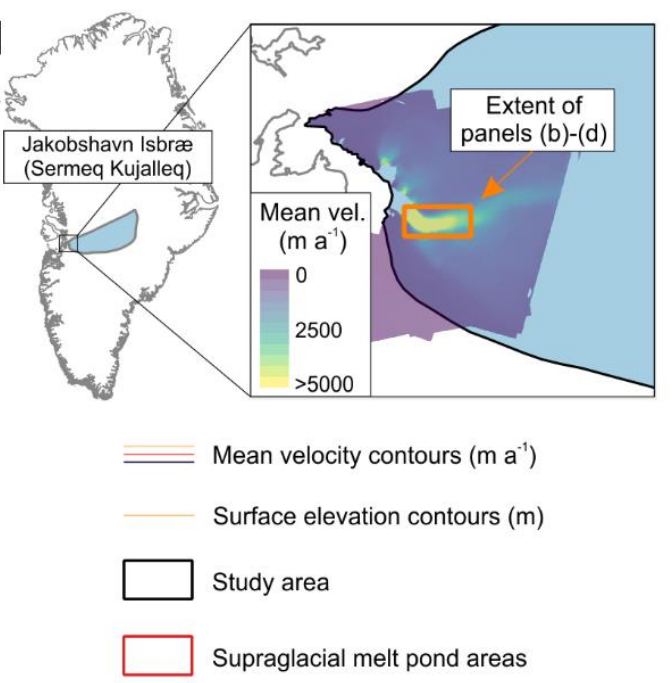

$$
\begin{aligned}
& \text { Bed elevation (m) } \\
& \begin{array}{|l|l}
\hline & 125-300 \\
-50-125 \\
-225--50 \\
-400--225 \\
-575--400 \\
-750--575 \\
-925--750 \\
-1100--925 \\
-1275--1100 \\
-1450--1275 \\
<=-1450
\end{array}
\end{aligned}
$$
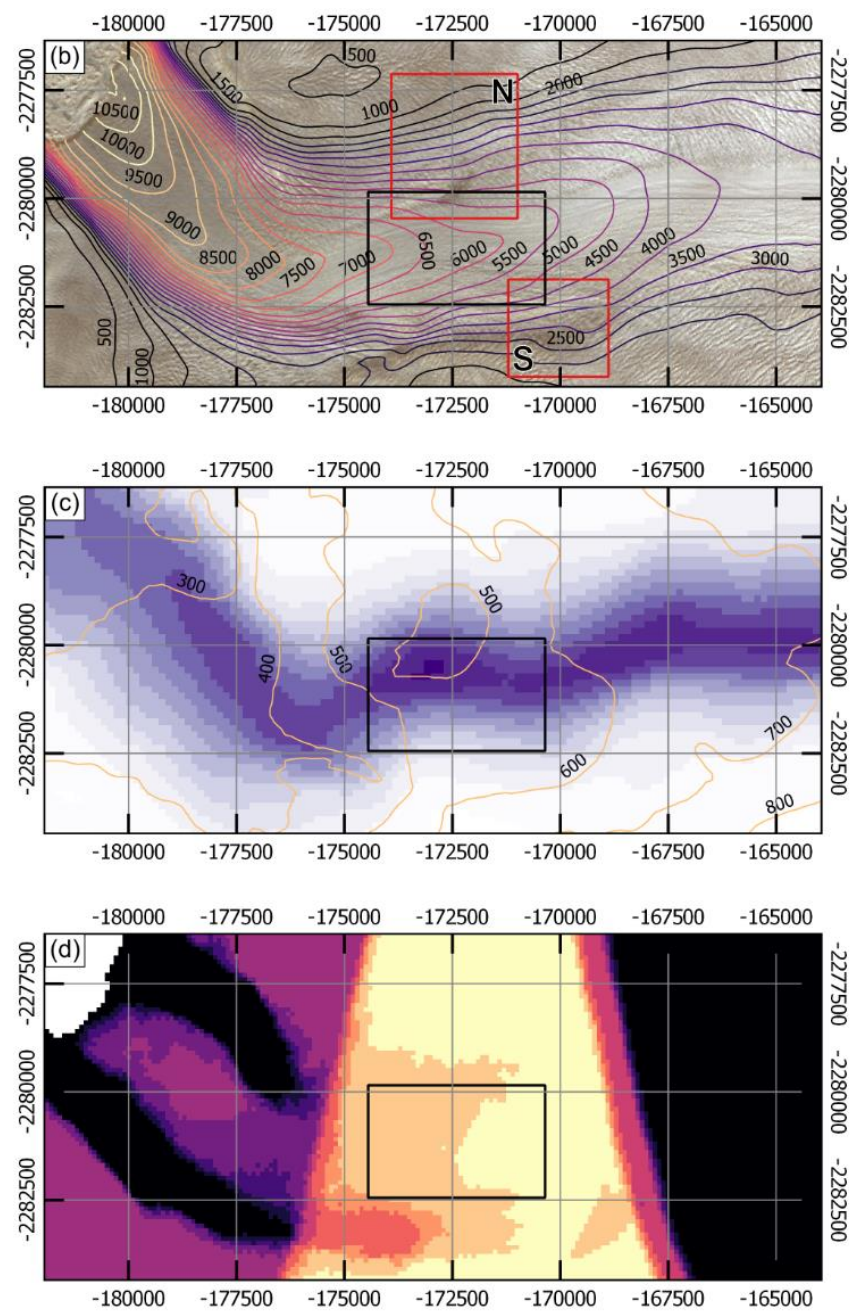

Figure 2: Summary of SK-JI and study area. (a) Location of SK-JI and mean velocity of "W69.10N" (Joughin et al., 2020b) v3 dataset. (b) Landsat image of most retreated SK-JI position (Sept-2013), contours of the Joughin et al. (2020b) velocity dataset, study area of this study (black box) and the extent of the two boxes (red) used to characterise local meltwater pond behaviour. (c) basal and surface topography (Morlighem et al., 2017). (d) spatial coverage of SAR ice velocity dataset of Joughin et al. (2020b). Projection for b-c is epsg: 3413.

\subsubsection{Data processing and POD}

160 We prepare the dataset by reading in each ice velocity raster and saving a "stack" of colocated images, and a table of relevant metadata including raw filename, image pair dates, separation, and centre-dates. In MATLAB R2020a the $i-j-t$ stack is then rearranged into the form of $\mathbf{X}$ (Eq. 1). Some small gaps exist in the satellite-derived velocity data, in the very southwest corner of our study area 4 measurements are missing in the pixel time series', and over the vast majority of the study area only 1 measurement is missing. To fill-in these minor gaps we interpolate temporally the satellite-derived ice velocity measurements using D'Errico, (2020). We then resample the velocity measurements using a piecewise, non-overshooting cubic interpolation 
https://doi.org/10.5194/tc-2021-184

Preprint. Discussion started: 12 July 2021

(c) Author(s) 2021. CC BY 4.0 License.

(c) (i)

(Akima spline) to be regularly spaced according to the median measurement gap (5 days). A SVD of this matrix is then calculated and a three-value moving average taken of $\mathrm{V}$ to dampen very high frequency fluctuations. These fluctuations are potentially due to some measured velocities being derived from image pairs closely spaced in time, but collected with ascending and descending orbits, noted to result in velocity discrepancies in some areas by Riel et al. (2021). The velocity matrix is then reconstructed (i.e. the inverse of Eq. 1), and the mean of each pixel timeseries subtracted to find the velocity anomaly of the whole dataset. The POD is then performed as in Section 2.1 and Figure 1. A MATLAB script for this procedure is provided with this manuscript.

\subsection{Characterisation of surface hydrology}

175 To test whether melt-season velocity fluctuations can be attributed to surface-to-bed glacial hydrology, as in Mair et al. (2002), we use satellite imagery within Google Earth Engine to characterise daily supraglacial meltwater pond behaviour. We focus on two immediately upstream sub-regions (Figure 2) where ponds form quasi-annually, these correspond to the "saturated crevasses" CV2 and CV5 identified by Lampkin et al. (2013) as forming in 2007 and delivering enough meltwater during drainage to enhance basal sliding in a distributed subglacial hydrological system. We assume that rapid changes in ponded water extent corresponds to spatially and temporally focussed delivery of meltwater to the ice bed.

To begin, we derive outlines of the maximum annual supraglacial melt pond extent for the melt season (1 May to 30 September, 2009-2019) from daily Moderate Resolution Imaging Spectroradiometer (MODIS) Terra images within Google Earth Engine (Gorelick et al., 2017). Level-2 MOD09GQ band 1 surface-reflectance data (250 m resolution) were cloud masked where coincident band 7 (500 m resolution resampled to $250 \mathrm{~m}$ resolution) reflectance values exceeded 0.09 . Supraglacial melt ponds were defined using a dynamic threshold approach (Selmes et al., 2011; Williamson et al., 2017), where a central pixel's value had a reflectance of less than 0.65 against the mean reflectance within a moving 21 -by-21 pixel window.

These daily supraglacial melt pond area masks were subsequently summed to create annual composites of maximum melt pond extent and false positives were removed where the ponded water either did not appear twice within six successive days from first appearance; was not observed during a period of five cloud-free days before the third occurrence; did not appear on three or more occasions over the melt season; or was observed on more than $50 \%$ of cloud free days, acting to remove land or protruding bedrock (Liang et al., 2012; Cooley and Christoffersen, 2017).

195 We then create the two study areas around the maximum melt pond extents 2009-2019 for high-resolution temporal analysis (Figure 2b). Here we analyse daily MODIS imagery within these two subregions using the thresholding method above, recording the cloud cover and the "melt pond" area within each box. Importantly, we are unable to perform the same stringent quality control procedures on the daily record as on the annual record as it is limited by cloud cover, and, potentially, shadows 
https://doi.org/10.5194/tc-2021-184

Preprint. Discussion started: 12 July 2021

(c) Author(s) 2021. CC BY 4.0 License.

(c) (i)

due to the rough crevassed terrain. Consequently, we reject the highest $5 \%$ of values as spurious, and all measurements when

cloud cover over each subregion is $>10 \%$. We identify potential drainages qualitatively when no melt pond area is consistently detected after a period of consistent melt pond detection. Comparison of these dates with available corresponding $30 \mathrm{~m}$ spatial resolution Landsat-7 and -8 imagery demonstrates we accurately bracket major melt pond drainage events (Appendix A).

In addition to the remote sensing approach outlined above, we use runoff output from the Modèle Atmosphérique Régional (MAR) v3.11 (ftp://ftp.climato.be/fettweis/MAR/) extracted from the SK-JI catchment (Mouginot \& Rignot, 2019) and portioned into $500 \mathrm{~m}$ elevation bands using the dataset's surface height layer to characterise the seasonal runoff in, and upstream, of our study region.

\subsection{Ancillary data}

210 We draw upon several open datasets to aid interpretation of POD results: dates rigid melange is present in front of SK-JI and relative terminus position from Joughin et al. (2020b), and topographic datasets from BedMachine v3 (Morlighem et al., 2017). From these topographic datasets we estimate the subglacial water flowpaths by calculating subglacial flow accumulations (using Schwanghart \& Scherler, 2014) from the Shreve (1972) hydraulic potential surface where ice-bed effective pressure is zero.

\section{Results and interpretation}

\subsection{POD}

The decomposed dataset is shown in Figure 3 and Mode 1 dominates the POD results. Its spatial weighting broadly reflects the mean ice velocity pattern (Figure $3 \mathrm{~b}$ ) and its temporal coefficient peaks annually in late summer and reaches its minima in spring. This is confirmed by the power spectral density (Figure 3c) showing an almost exclusive annual periodicity. There is no negative spatial weighting, meaning the entire study area increases (spring to summer) and decreases (autumn and winter) in-phase, with a higher seasonal amplitude in the downstream of the study area.

Modes 2 and 3 show similar spatial structures with positive weighting to the west (down glacier) of the study area and negative weighting in the east of the study area (up glacier). This indicates a switching velocity differential across our study area, where one area shows above average velocities due to this mode while another shows below average velocities. Their temporal coefficients show annual periodicity and, generally, peak temporally in summer and have troughs during winter. Importantly, the temporal coefficients resemble quasi-conjugate pairs, in that they have similar $S(\%)$ values and higher-frequency components appear mirrored in one another. For example, during the series of peaks in winter-2012 to spring-2013, and the major signal excursion autumn-2014. Higham et al. (2018) showed that similar modal pairs in decomposed particle image 
https://doi.org/10.5194/tc-2021-184

Preprint. Discussion started: 12 July 2021

(c) Author(s) 2021. CC BY 4.0 License.

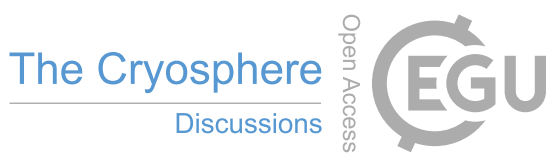

(c) (1)

230 velocimetry datasets relate to the formation of the von Karmen street in the lee of a flow obstacle. This indicates a common, but spatially variable or moving, process is responsible for Modes 2 and 3 in our dataset. When summed these quasi-conjugate pairs may provide a picture of the overall distribution of the process responsible, we investigate this further during POD interpretation (Section 3.2).

235 Modes 4 and 5 show some common spatial structures, but no clear periodicity. Broadly spatial weightings are negative in the central east-west axis of the study area and negative towards the study area margins. The most prominent feature is the N-S narrow band of very high absolute values to the west of the study area. Mode 6 and lower modes show no discernible spatial structure either temporally or spatially, and account for a very small amounts of the dataset variance. 
(a) POD spatial weighings
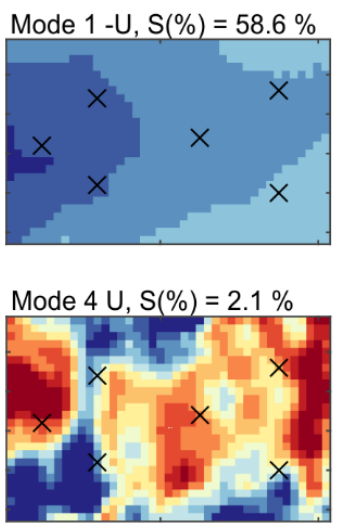
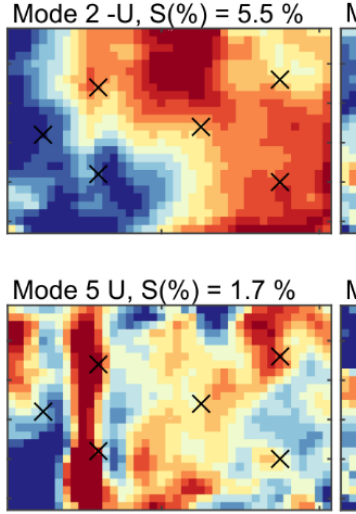

Mode $5 \mathrm{U}, \mathrm{S}(\%)=1.7 \%$

$-0.05$

0.05

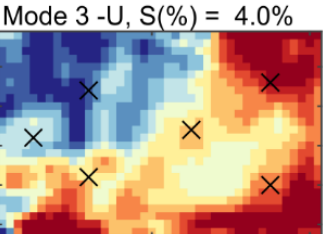

Mode $6 \mathrm{U}, \mathrm{S}(\%)=1.3 \%$

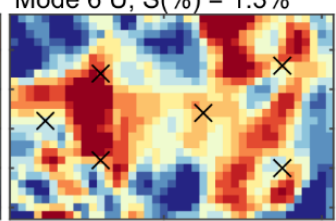

(d) POD temporal coefficients

(b) Mean vel. ( $\mathrm{m} \mathrm{a}^{-1}$ ) during study period

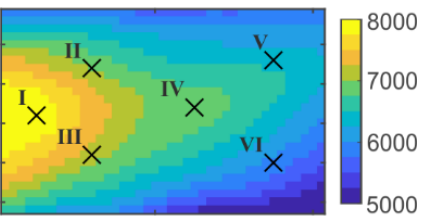

(c) Spectral content of temporal coef.

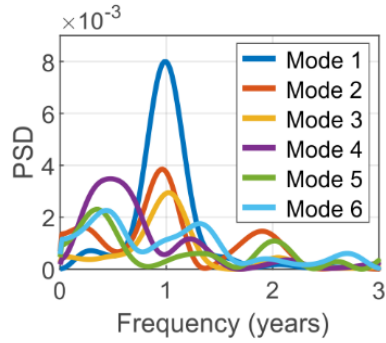

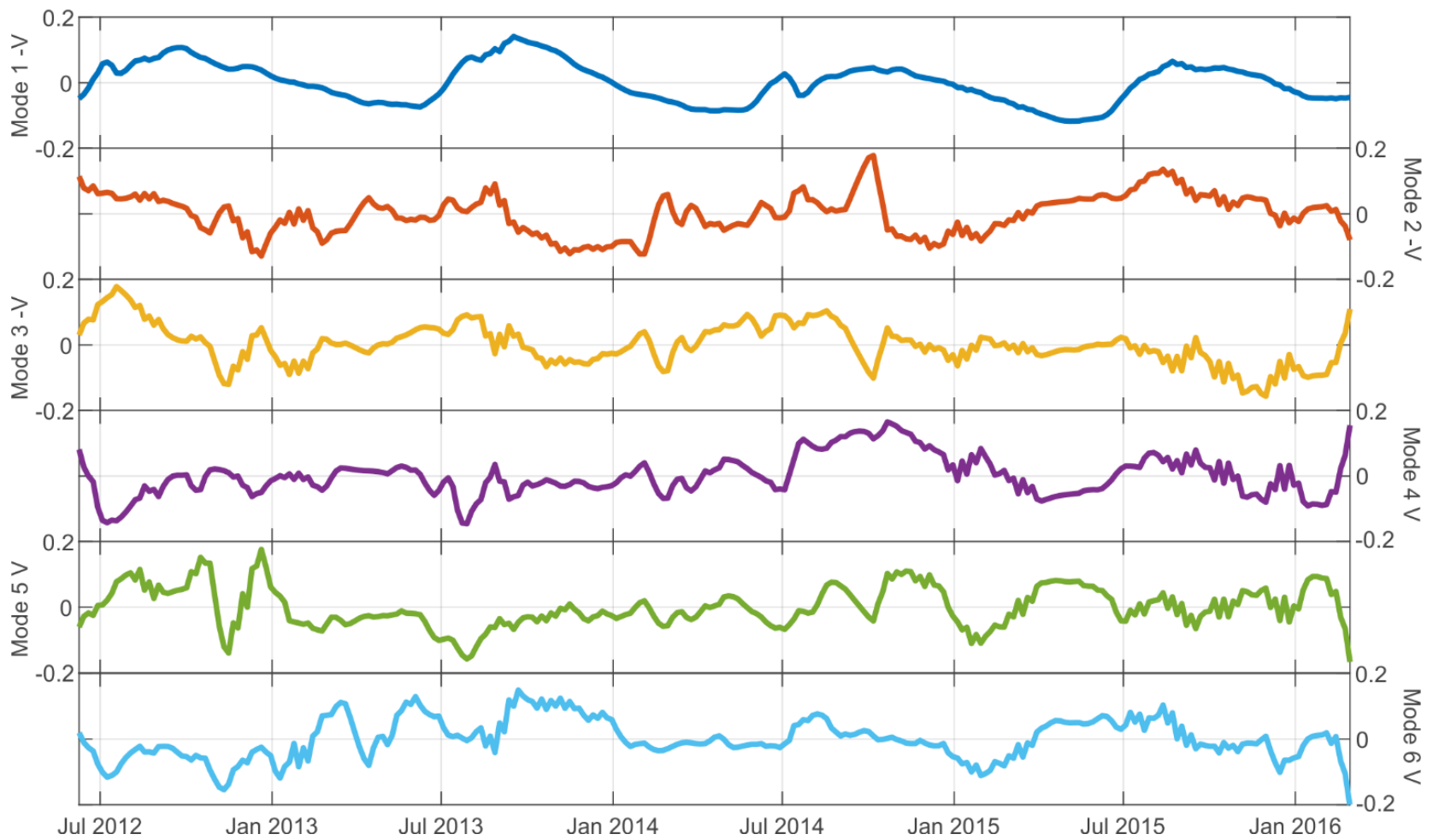

Figure 3. (a) The spatial weightings $U$ for Modes 1 - 6. (b) Mean velocity of decomposed dataset and locations of representative points discussed later in this manuscript. Note that this is overall higher than the mean of the whole SAR-derived dataset which is not resampled, and includes years of lower average velocity. (c) Power spectral density, or PSD, of the POD temporal coefficients. (d) The temporal coefficients, $\mathrm{V}$, for Modes $1-6$. To aid the interpretation of seasonality the sign (+/-) of Modes 1-3 are reversed such that $V$ peaks in summer, because this is applied to both $U$ and $V$ this has no effect on the results. 


\subsection{Interpretation}

The modes extracted from the decomposed dataset are purely statistical features and do not necessarily bear any relation to glaciological processes. In this subsection we compare the spatial modes and temporal coefficients with complementary glaciological and environmental datasets to assess whether the forcing from particular glaciological and environmental processes may contribute to the patterns revealed by the POD analyses. We also interrogate the published errors of the original ice velocity dataset to ensure that we do not attach unwarranted glaciological significance to features in the decomposed dataset.

\subsubsection{Glaciological and environmental factors}

In Figure 4 we compare the temporal coefficients (V; Figure 4a) with a variety of potential glaciological forcing mechanisms. Mode 1 has a strong seasonal cycle that tracks the advance and retreat of the terminus position (Figure 4e), following the increase in seasonal velocity amplitude observed in 2012 and 2013, before starting to decrease (Lemos et al., 2018). The peak value of the coefficient in each year coincides with the minimum terminus position in late summer. Annual peaks occur at 26Sept-2012; 16-Sept-2013; 6-Oct-2014; and 22-Aug-2015. Even small fluctuations in the terminus position are reflected in the Mode 1 V: for example, in mid Dec 2012 and late August 2015 short-term retreats in terminus position correspond with small positive deflections in Mode $1 \mathrm{~V}$. Mode 1 does lag slightly behind terminus position change (Figure 4e): likely the adjustment time for the stress perturbation to reach our upstream study area. This supports an interpretation that Mode 1 reflects the dynamic enhancement and adjustment due to the changes in terminus stress associated with variations in calving or grounding line position. This physical interpretation of Mode 1 explains its dominance $(S(\%)=58.6)$ and the increase in the positive spatial weighting in the direction of the calving terminus. This is expected as several other authors have also noted that stress reconfiguration due to frontal ablation dominates the bulk velocity signal of SK-JI (e.g. Joughin et al., 2020a; Khazendar et al., 2019; Lemos et al., 2018; Bondzio et al., 2017). Figure 5 shows secondary early summer peaks in the velocity at points IVI also reflected in Mode 1. The cause of these peaks are not simply attributable to terminus position change or any forcing mechanism, both occur in the highest two melt years and so may be due to meltwater input. That these are in Mode 1 indicates a widespread decoupling of the bed due to early season melting and subsequent pressurisation of the subglacial hydrological system, similar to "spring events" first seen on valley glaciers (Mair et al., 2003; Iken et al., 1983). 
https://doi.org/10.5194/tc-2021-184

Preprint. Discussion started: 12 July 2021

(c) Author(s) 2021. CC BY 4.0 License.
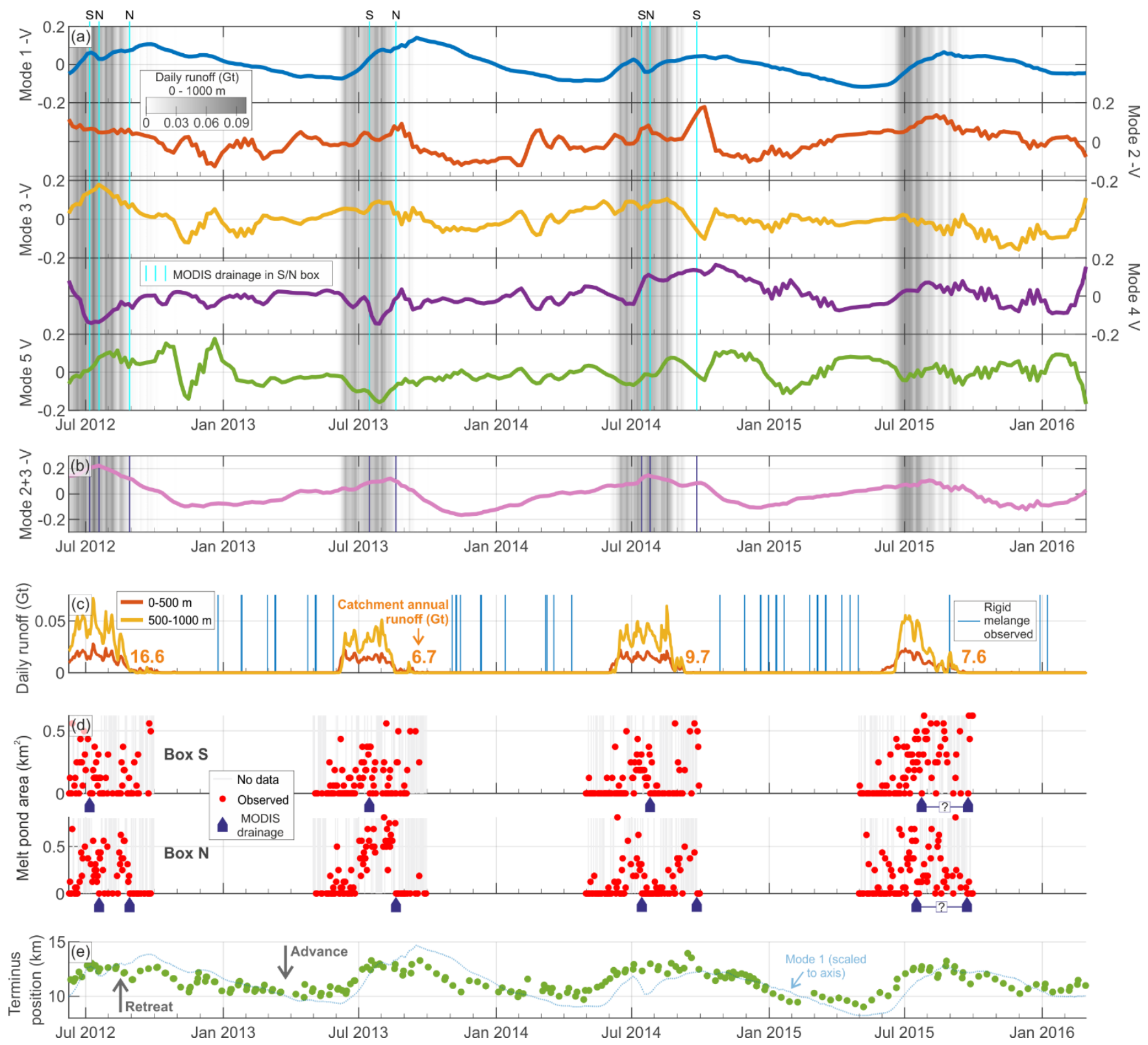

Figure 4. Temporal comparison of POD modes and environmental forcing. (a) Temporal coefficients, V, of Modes 1-5, which show some identifiable temporal or spatial coherence. Shading is level of runoff [see panel c] and light blue lines indicate potential supraglacial melt point drainages [see panel d]. (b) $\mathrm{V}$ of Modes 2 and 3 summed showing a strong seasonal underlying process that peaks in the mid/late runoff period. (c) Runoff output from MAR v3.11 (ftp://ftp.climato.be/fettweis/MAR/) for two elevation bands, and for the total catchment; blue bars indicate observed periods of rigid melange after Joughin et al. (2020b). (d) area of box $\mathrm{S}$ and $\mathbf{N}$ (Figure 1b) covered by a melt pond and where rapid and consistent drops in meltwater area are interpretated as melt pond drainages; grey bars denote rejected data (see Section 2.3). (e) SK-JI terminus position from Joughin et al. (2020b) with higher (lower) values indicating a more retreated (advanced) position, for illustrative purposes Mode $1 \mathrm{~V}$ is scaled and overlain. 
https://doi.org/10.5194/tc-2021-184

Preprint. Discussion started: 12 July 2021

(c) Author(s) 2021. CC BY 4.0 License.

(c) (i)

285 Following from our interpretation that Mode 2 and 3 are quasi-conjugate pairs, i.e., they are strongly related by a common process but with features shifted in phase, in Figure $4 \mathrm{~b}$ we sum of Modes 2 and 3 (herein referred to as Modes 2+3) to gain an overall picture of the timing of the process responsible. Higham (2018) discuss the occurrence of paired modes in the POD of natural flows in detail. The pattern of Modes $2+3$ is strongly seasonal indicating a glaciological process, rather than being an obvious artefact. The timing of the seasonality contrasts to Mode 1 however with Modes 2+3 peaks at 18-July-2012; 12-Aug-

290 2013; 23-July-2014; and 2-Aug-2015, meaning Modes 2+3 peak, on average 50 days before Mode 1. Temporal coefficient, V, for Mode $2+3$ is most positive during mid-summer when both localised and catchment wide runoff reach their highest values, and when supraglacial drainage events occur. V is most negative in November/ December. These patterns indicate that Mode 2+3 may be strongly influenced by dynamic responses to melt-induced, subglacial hydrological forcings. However, hydrological forcing is complex as it will reflect temporal and spatial variability in:

1) Different dominant modes of delivery of meltwater to the bed (e.g. Colgan et al., 2011), i.e.

a. short-term, spatially focussed, stochastic injections of large volumes of meltwater resulting from, typically immediately down-glacier from, supraglacial drainage events or large moulins, versus

b. temporally dampened, spatially-distributed routing of catchment-wide melt, typically captured by crevasse fields and directed along subglacial pathways determined by subglacial hydraulic potential.

2) Different dominant subglacial drainage system types (e.g. Andrews et al, 2014), i.e.

a. Hydraulically efficient, channelised drainage systems predominantly experiencing low water pressures, versus

b. Hydraulically inefficient, distributed drainage systems predominantly experiencing high water pressures.

305 In Figure 5 we plot the point velocity series for each of the representative points (I-VI). The annual peak SAR-derived measurements are at 27-Sept-2012; 14-Sept-2013; 3-Oct-2014; and 18-Aug-2015: very closely matching the Mode 1 peaks at 26-Sept-2012; 16-Sept-2013; 6-Oct-2014; and 22-Aug-2015. On close inspection of Figure 5 the mid-melt-season secondary peak is observable in three of the four years and occurs on 11-July-2012; 01-Aug-2013 and 26-Jun-2014: close to the Mode $2+3$ peaks. This suggests Modes 2 and 3 are related to these features in the non-decomposed velocity record, however, we note 310 these mid-melt season peaks are also partially represented in Mode 1, suggesting that each Mode does not completely reflect distinct glaciological processes. 
https://doi.org/10.5194/tc-2021-184

Preprint. Discussion started: 12 July 2021

(c) Author(s) 2021. CC BY 4.0 License.

(c) (i)
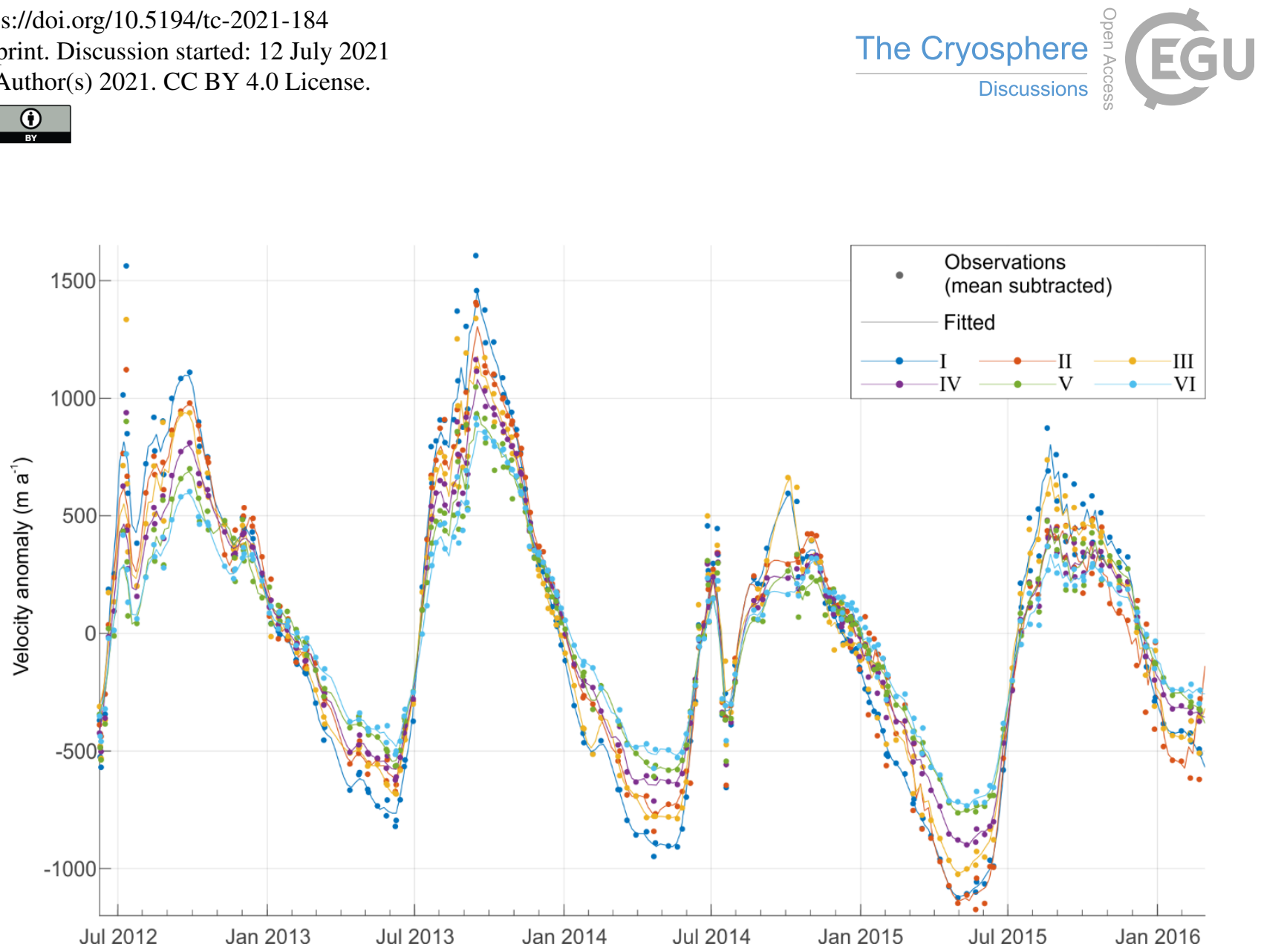

315 Figure 5. Measured and resampled velocity anomaly time series at Points I-VI referred to in Figure 3.

One powerful use of POD is the ability to reconstruct the dataset using only selected modes: allowing us to see the combined effect of Modes 2 and 3 on ice velocity. In Figure 6a-c we compare Modes 2 and 3 U, and the locations of persistent surface meltwater ponds and simple subglacial flowpaths after Shreve (1972). In Figure 6e the velocity due to Modes 2 and 3 is reconstructed at representative Points I-VI and compared to the temporal variation in supraglacial hydrology from Figure 4. The significance of this lies not in explaining the detail of temporal and spatial glacier dynamics within a relatively small area, but rather lies in assessing the extent to which the POD modes are capable of discerning hydrological forcings, even on a glacier where glacier geometry, mass balance regime and calving processes are more dominant.

325 We firstly discuss how different modes of delivery of water to the bed may influence the dynamic patterns revealed by Modes 2 and 3. Figure 6 reveals contrasting dynamic patterns between points I-III, which display high frequency variations superimposed on a broad annual cycle, and points IV-VI, which show fewer high frequency variations but a clearer annual cycle (Figure 6e). Points I, II and III are located down glacier of all the supra-glacial melt ponds and are most proximal to the northern area, $\mathrm{N}$, where the data indicate that ponded areas are larger and drainage events more frequent than the southern area, S (Figure 4d, A1). Consequently, these locations will be most influenced by hydrological forcing as described in type 1a above which would explain pronounced fluctuations in velocity anomalies some of which are clearly coincident with 
https://doi.org/10.5194/tc-2021-184

Preprint. Discussion started: 12 July 2021

(c) Author(s) 2021. CC BY 4.0 License.

identifiable meltwater drainage events. Points IV - VI display less short-term velocity variability as they sit downstream of the less active area $\mathrm{S}$. The different locations also vary in the sign of their dynamic response to potential melt pond drainage events, as identified in Figure 4d. For example, points I and III show an increase in velocity coincident with potential drainage events whilst point II shows a decrease in velocity coincident with these events. To explain this and other patterns we secondly discuss how subglacial drainage system structure affects dynamics, invoking well established conceptual models of their spatial and temporal evolution.

Shreve's subglacial flow accumulations (Figure 6c), derived from hydraulic equipotential mapping, indicate the likely preferential drainage axes (PDAs) within the study area. These are the broad axes along which temporally dampened, catchment-wide melt from upglacier will be directed during summer (i.e. type $1 \mathrm{~b}$ above), and where base-level water flow, generated from frictional melting, will flow throughout the year. Uncertainties in basal topography create uncertainties in the exact locations of PDAs (Mackie et al., 2021): hence in areas where multiple PDAs are confluent, we have higher confidence that these are areas of high hydrological activity. The dynamic response to hydrological forcing will vary through time as the drainage system evolves. Following Rothlisberger (1972), when discharge through these regions is consistently high (as would be likely during the summer melt-season), turbulent flow will develop which will provoke the development of channelised, low-pressure subglacial flow (i.e. type 2a above) with minimal impact on basal sliding and ice velocity. This would explain why Points IV, V and VI, which are located close to major confluences in flow accumulation, show negative velocity anomalies during the summer melt-seasons. The developed of channelised drainage at Point II (located directly over a PDA) also explains the negative velocity anomalies during drainage lake drainage events, as noted above. Conversely, during the rest of the year, all channels will have closed by ice deformation and the glacier will be underlain by an inefficient distributed drainage system (i.e. type $2 \mathrm{~b}$ above). During these periods, the areas with confluent PDAs will become the most likely areas of the bed to experience low magnitude, base-level water flows which will promote higher water pressures and enhanced basal sliding. Consequently, points IV, V and VI show positive velocity anomalies during the winter. The annual cycle of points I and III shows negative velocity anomalies during the winter which likely reflects their isolation from flow confluences and hence that they are likely to be located over poorly connected regions of the glacier bed where there is minimal hydrological forcing in the winter (following Hoffman et al., 2016). In summer, the forcings from high magnitude melt pond drainage events discussed above create positive velocity anomalies at points I and III since short-term, high magnitude discharge is forced into inefficient drainage systems, hence provoking high basal water pressures. Notable fluctuations in velocity seen at points I-III in December 2012 may be due to release of stored water from englacial or subglacial sources (Pitcher et al., 2020).

Despite the complex temporal and spatial modal patterns described by Mode 2 and Mode 3 we propose that together these modes do define the component of dynamic variability that is strongly influenced by changing patterns of subglacial hydrological forcings. The seemingly complex behaviour can be explained with recourse to long-held hydrological theory and simple conceptual models for meltwater delivery mechanisms and drainage system structures. If the POD analyses could be 
https://doi.org/10.5194/tc-2021-184

Preprint. Discussion started: 12 July 2021

(c) Author(s) 2021. CC BY 4.0 License.

performed over a larger spatial scale, or across a glacier that was less directly dominated by calving dynamics, then POD Modes might be defined that more obviously reflect subglacial hydrological forcing, similar to Mair et al. (2002). This will become possible as the temporal resolution and spatial extent of satellite derived glacier and ice sheet dynamics continues to improve.

(a) Mode $2-U$

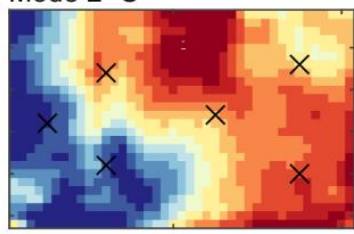

(b) Mode $3-U$

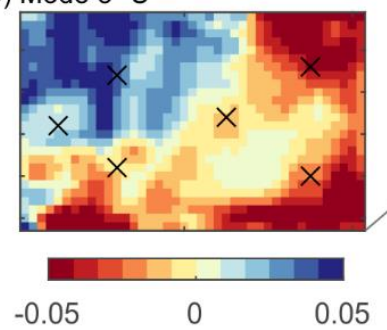

(c) -175000

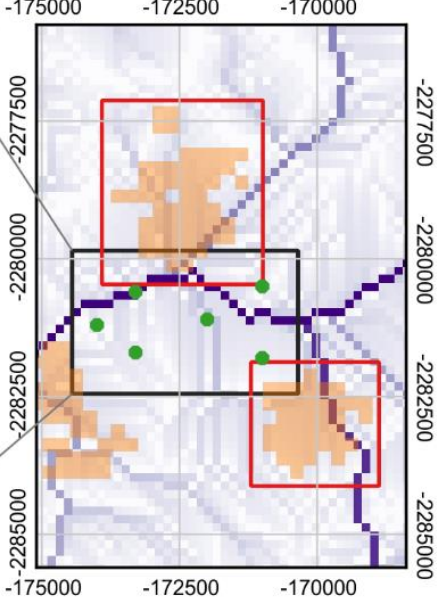

(d)

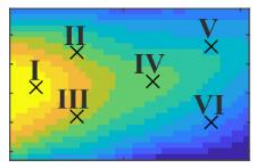

- Velocity point Melt pond area

Study area

Melt pond estimated max possible size (2009-2019)

0

1.5 Shreve subglacial

3 flow accumulations

4.5 ( $\log _{10}$ upstream cells)

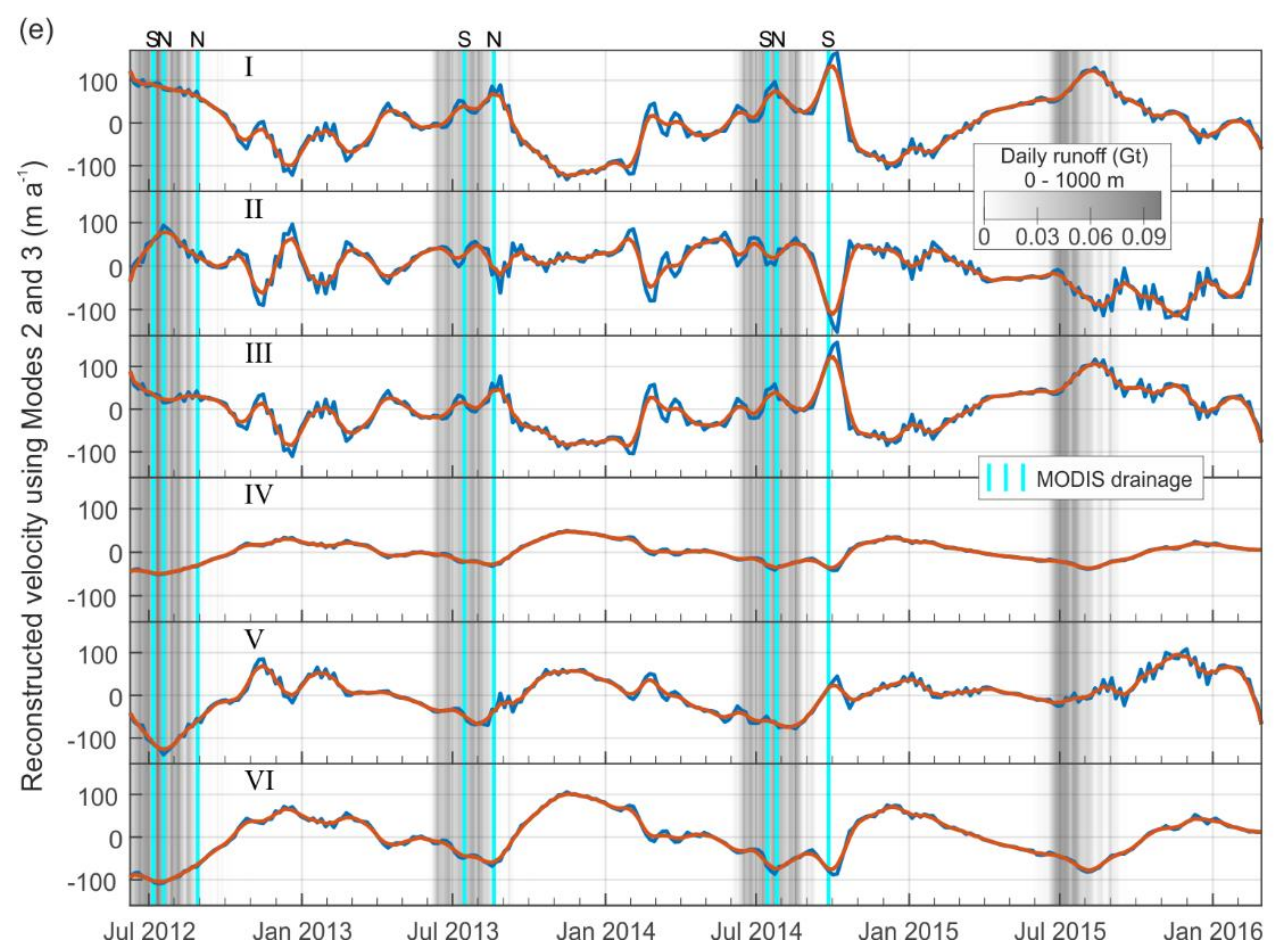

Figure 6. (a) Mode 2 -U. (b). Mode 3 -U. (c) Supraglacial melt pond locations and estimated subglacial hydrological routing (projection is epsg: 3413). (d) representative point locations with mean SAR-derived velocity. (e) Comparison of reconstructed velocity from Modes 2 and 3, runoff and drainage displayed in (a) as in Figure 4. 3-value (15 day) smoothed velocities in orange. 
https://doi.org/10.5194/tc-2021-184

Preprint. Discussion started: 12 July 2021

(c) Author(s) 2021. CC BY 4.0 License.

\subsubsection{SAR-derived velocity error analysis}

375 In this subsection we consider the errors of the SAR velocity product itself, interpolated to a regularly sampled time series of ice velocity for POD. In Figures $7 \mathrm{a}-7 \mathrm{~d}$ we plot the published errors of the velocity dataset of Joughin et al. (2020b). Error magnitudes are calculated from the error components. We see no clear qualitative correspondence between these statistics summarising the velocity product errors and Modes as shown in Figure 3. In Figure 7e we investigate the pixel-by-pixel correlation of these maps of summary statistics with Modes 1-6. We see low or negligible correlations with SAR velocity errors suggesting they do not affect the POD, the strongest correlation is with median error and Mode $4 \mathrm{U}(\mathrm{r}=0.42)$. Since this pattern is apparent in Mode 4 (Figure 3a), and its shape is sharp and likely non-glaciological we propose that a secondary use for POD analyses may be to identify small spatial biases in ice flow fields relating to processing or environmental noise. We conclude that our POD results, and therefore our glaciological interpretations, are not strongly influenced by small nonglaciological biases in the SAR-derived ice velocity dataset.

(a) Median error $\left(\mathrm{m} \mathrm{a}^{-1}\right)$

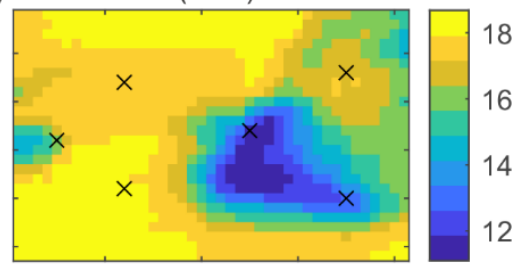

(c) Error minimum $\left(\mathrm{m} \mathrm{a}^{-1}\right)$

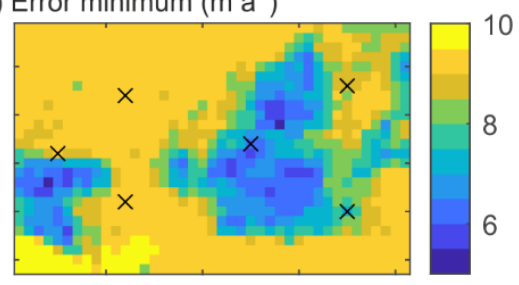

(b) Error interquartile range ( $\mathrm{m} \mathrm{a}^{-1}$ )

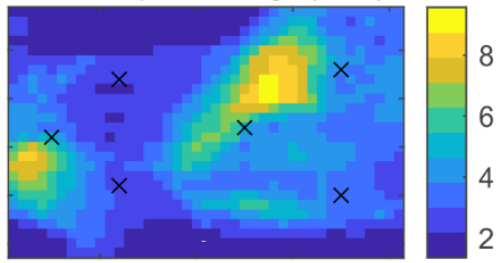

(d) Error maximum $\left(\mathrm{m} \mathrm{a}^{-1}\right)$
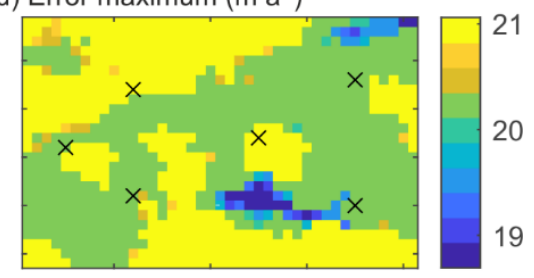

(e)

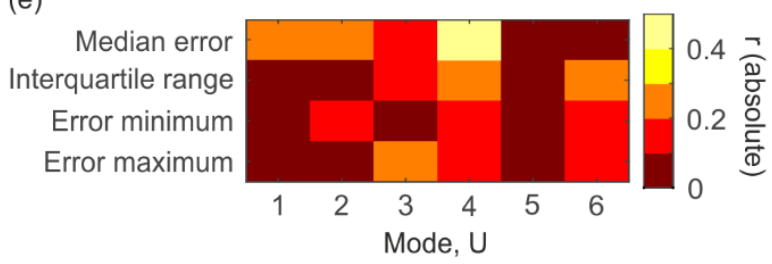

Figure 7. (a-d) Summary statistics of errors of the SAR-derived velocity dataset. (g) correlations of other panels with Modes 1-6. 
https://doi.org/10.5194/tc-2021-184

Preprint. Discussion started: 12 July 2021

(c) Author(s) 2021. CC BY 4.0 License.

(c) (i)

\subsubsection{Interpretation Summary}

390 To summarise, Mode 1 relates strongly to the terminus driven variability that is known to strongly dictate the bulk observed velocity signal of SK-JI. Modes 2 and 3 together describe the seasonal development of the spatially variable subglacial hydrological system influenced by episodic input of meltwater and the increasing efficiency of the subglacial hydrological system during summer melt. Mode 4 shows some spatial correspondence to the SAR dataset errors, indicating that POD could potentially be additionally used to identify non-glaciological, methodological biases or errors in surface ice velocity datasets. Mode 5 and lower show no interpretable spatial or temporal patterns and therefore likely do not contain useful statistical information.

\section{Discussion}

The work presented here is an important contribution to efforts to explain how patterns of ice motion, observed from space, can reveal different glaciological forcing mechanisms. As the outlet glaciers of Greenland retreat, and their geometry and flow evolves, it is likely that the relative importance of processes governing their ice dynamics will also evolve, though this is less easily assessed. This study acts as a proof of concept, building on the work described by Mair et al. (2002), that the eigendecomposition of ice velocity can detect the influence of changes in glacial hydrology on ice dynamics. Figure 6 shows that hydrologically-forced flow contributes to velocity variabilities of approximately $\pm 100 \mathrm{ma}^{-1}$ to the ice flow in our study area of SK-JI. This contribution varies seasonally but also in response to sudden inputs of meltwater.

Our study area within SK-JI was chosen owing to the excellent and openly available ice velocity dataset, but it is arguably not the ideal place to test the applicability of POD to ice velocity due to the dominance of stress patterns created by changing terminus geometry on the overall seasonal velocity, as outlined by previous work (Joughin et al., 2020a; Lemos et al., 2018; Bondzio et al., 2017). The application of POD analyses to a velocity record from a marine-terminating glacier with seasonal behaviour more influenced by subglacial hydrology such as Kangiata Nunaata Sermia (e.g. Davison et al., 2020, Sole et al., 2011) or a land terminating section of the ice sheet, especially one with complementary discharge measurements such as Russell and Leverett Glacier (e.g. Davison et al., 2019; Chandler et al., 2013) might yield more insights into their hydrodynamic coupling behaviour. This underlines the importance of continued production of high-resolution, all-year SAR datasets of ice velocity in key, dynamic areas. Practically this involves the continued exploitation of Sentinel 1 and TerraSAR-

$415 \mathrm{X} /$ TanDEM-X for ice velocity and, looking forward, to future missions such as NASA-ISRO SAR (NISAR).

In this analysis we only characterise supraglacial melt pond drainages in the immediate locality of our study area and find these appear to explain the melt season Modes 2 and 3 excursions in ice velocity. This implies that drainages farther upstream have little effect on the short-term velocity variability at this location. At Sermeq Kujalleq (Store Gletsjer), the drainage of supraglacial lakes has been shown to rapidly increase the efficiency of the subglacial drainage system and decrease ice velocity 
https://doi.org/10.5194/tc-2021-184

Preprint. Discussion started: 12 July 2021

(c) Author(s) 2021. CC BY 4.0 License.

(c) (i)

at a point near the terminus (Howat et al., 2010), strengthening our interpretation in this study that the drainage of supraglacially ponded water can both slow and enhance ice velocity. The interpretation of decomposed surface velocity fields presents a potential method for comparing field data to model output in a more developed manner than straightforward correlations. We propose comparing low-dimensional representations of measured ice velocity (i.e. separated POD Modes) with ice sheet model outputs calculated with differing parameterisations of subglacial hydrology and basal motion. This would provide a means of assessing the efficacy of models to account for spatially and temporally variable hydro-dynamic coupling, ultimately leading to more physically robust predictions of future ice sheet behaviour.

The POD technique applied here is complementary to that of Riel et al. (2021), who also decomposed the ice velocity record of SK-JI as imaged by TanDEM-X and TerraSAR-X from Joughin et al. (2020b; 2010). In that study the velocity time series of a wider area is decomposed into the seasonal cycle and transient multi-annual parts to show the propagation of a kinematic wave emanating from the glacier terminus. In this study we have isolated years where data stationarity can be reasonably argued, essentially removing the multi-annual transient, as a result our Mode 1, primarily due to seasonal terminus fluctuations, is broadly analogous to their seasonal velocity signal. Our Modes 2 and 3, that apparently relate to glaciohydrological

435 processes, however, occur on shorter timescales than the seasonal signal extracted by Riel et al. (2021). Riel et al. (2021) show that their B-spline approach can be used to detrend multi-annual velocity variations. This raises the prospect of applying POD to the reconstructed seasonal velocity only. This could address the issue of stationarity that limits the applicability of POD on datasets with long-term trends: a common feature of ice velocity time series. One consideration that might complicate this, however, is that in the four years analysed in this study, the influence of subglacial hydrology appeared to be split into a set of 440 quasi conjugate pairs of Modes (Section 3.1). Therefore, over a longer time period, one may expect that the influence of hydrological forcing on spatial patterns of ice motion may be divided across many more separate modes which would obfuscate physical interpretations. Future work could investigate this effect further, potentially using POD to focus on key glaciological features (e.g. supraglacial lakes, subglacial lakes, patterns of basal drag and/or ice stream sticky spots) over timescales that capture their dynamism.

\section{Conclusions and outlook}

In this study we have presented the first application of proper orthogonal decomposition (POD) to a series of satellite-derived maps of ice velocity. By focussing on an exceptionally well-sampled area of the SK-JI trunk from 2012-2016 (Joughin et al., 2020b) we significantly develop the POD/EOF analysis using survey stake observations of ice velocity on Haut Glacier d'Arolla by Mair et al. (2002) and apply it to a Greenlandic marine-terminating glacier.

We explored statistical structures or "Modes" in the data that partially explain dataset variance. The first Mode 1 clearly relates to the bulk velocity signal that previous researchers have shown links strongly to terminus-driven stress reconfiguration, 
https://doi.org/10.5194/tc-2021-184

Preprint. Discussion started: 12 July 2021

(c) Author(s) 2021. CC BY 4.0 License.

(c) (i)

transferred upstream rapidly due to low bed and lateral resistance (Joughin et al., 2020a; Bondzio et al., 2017). However, a second seasonal pattern exists which we hypothesise is due to glacio-hydrological processes. We present independent evidence

from remote sensing and several published datasets to support this interpretation and explain the observations in terms of proximity to the confluences of subglacial preferential drainage axes and the input of meltwater to the subglacial environment from two nearby supraglacial melt ponds. Short-term dynamism of glaciers is often explained in the context of evolving subglacial drainage systems and with respect to the manner of water delivery to the bed. Our POD analysis offers a powerful means to disentangle such complex influences from other higher-order drivers of ice dynamics. The decomposed Modes may contain some small artefacts that relate to the original dataset and its errors, but these are minor and do not affect our interpretation of the decomposed dataset. As ice velocity measurements continue to increase in spatiotemporal resolution and continuity, these will likely reduce in the future.

POD, and potentially related decomposition techniques such as dynamic mode decomposition (Schmid., 2010), are flexible, powerful and quick techniques that can be applied to other colocated measurements of ice surface velocity, derived from satellites, time-lapse imagery or GPS stake networks. The next step is to apply POD to other high-resolution records of ice surface velocity from glacier systems with a different balance of processes. Where hydrology is a more important control on the overall velocity pattern, its associated modal expression would be more dominant. We have applied POD only to the ice velocity magnitude, however, extending the analysis to polarstereographic grid $x$ and $y$ components is relatively simple and may provide insights to explain ice velocity patterns in the vicinity of key glacio-hydrological features. Furthermore, POD may offer a low-dimensional method of comparing surface velocity measurements with coupled glacier hydrology and ice dynamics models that simulate hydrological and ice dynamic processes explicitly and coincidently. We assert that computationally lightweight modal decomposition techniques such as POD can become a key method in illuminating the effects of individual glacial processes on combined emergent patterns of ice dynamics.

\section{Appendix A}

To evaluate the results of the daily MODIS dynamic thresholding method as outlined in Section 2.3, we compare U.S. Geological Survey Landsat-7 ETM+ band 4 and Landsat-8 OLI band 5 scenes with < $30 \%$ cloud cover either side, and close to, the drainage dates detected using the daily MODIS thresholding method as shown in Figure 4. This acts as a validation of the automated Google Earth Engine approach, and that the daily, but relatively low resolution, MODIS can detect melt pond drainages in this setting. It is important to note that the time between identified drainage and a suitable Landsat-7/8 image acquisition varies considerably, and this must be considered when comparing the two datasets. Furthermore, due to the large contrast in spatial resolution between MODIS $(250 \mathrm{~m})$, and Landsat-7 and $-8(30 \mathrm{~m})$ we expect some disparity between the 
https://doi.org/10.5194/tc-2021-184

Preprint. Discussion started: 12 July 2021

(C) Author(s) 2021. CC BY 4.0 License.

two approaches. The overall aim here is to increase confidence that the timing of the delivery of meltwater from the surface,

to englacial, and ultimately the subglacial environments, is correctly bracketed.

Results are shown in Figure A1. In the less active, southern melt pond area one drainage event is identified per year, occurring in July. For 2012 and 2013, drainages S1 and S2 in Figure A1, the available images show a slightly smaller ponded area indicating that only a partial drainage took place or refilling partially occurred in the days after drainage and before the Landsat acquisition. The 2013 drainage, S3, however is well identified by our technique. In 2012 and 2013 a secondary drainage (Figure A1c-d and A1j-k) takes place. These are visible in Figure 4d as a short return to zero melt-pond area conditions after short periods of consistent meltwater detection, but these were not judged to be clear enough for identification as a potential drainage event during analysis (Section 2.3). In both these cases however, drainage corresponds closely to the drainage of the larger, more active, northern melt pond area which is, in all cases, well-identified with the MODIS-derived record. In totality, this comparison increases our confidence in our approach correctly identifies melt water leaving the ice surface and, in turn, our interpretation that Modes 2 and 3 are strongly influenced glacier hydrology.

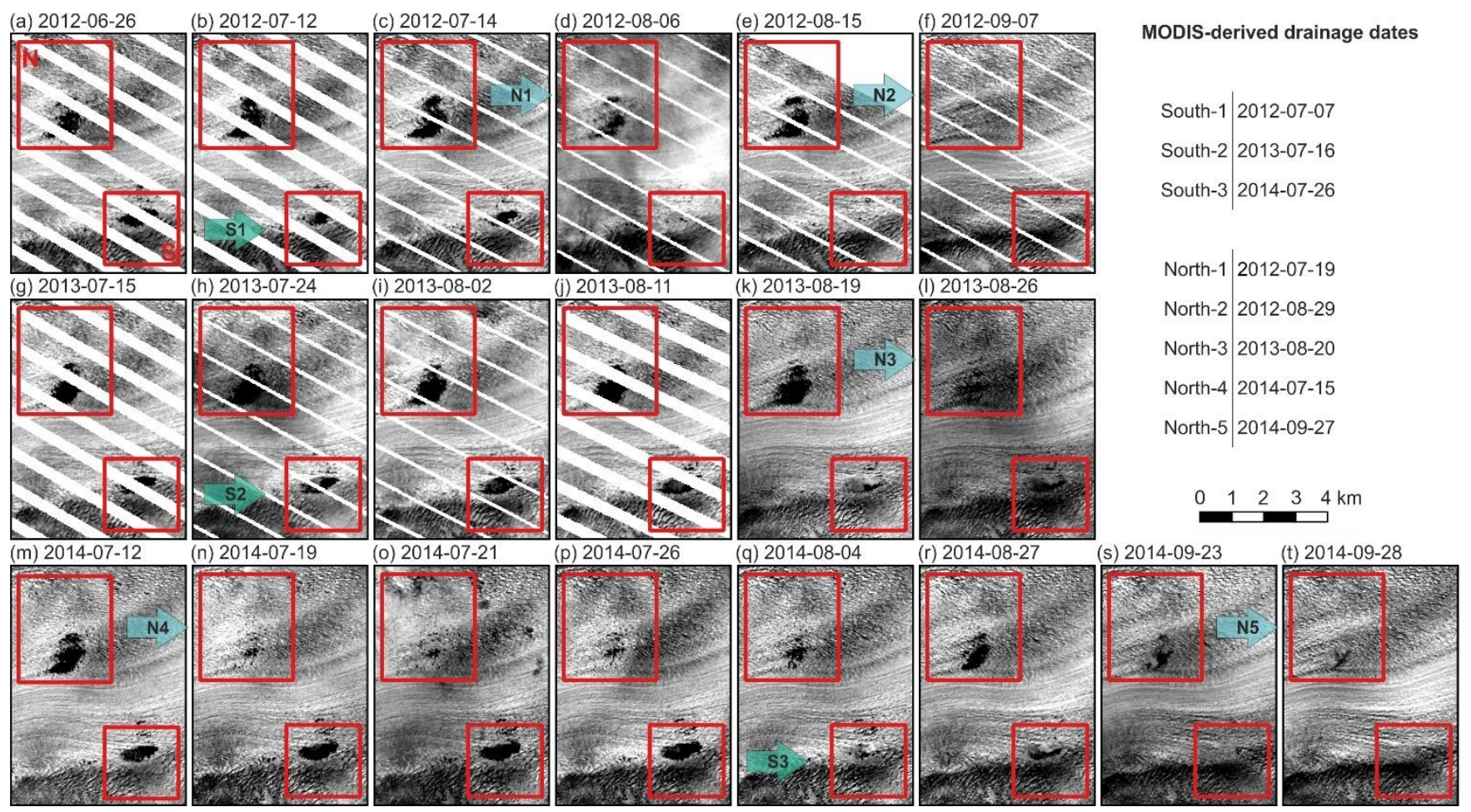

Figure A1. Satellite images of the South $(S)$ and North $(N)$ melt pond study regions, outlined in red (Figure 1b). Pooled water is indicated by flat, black regions. Panels a-j imagery from Landsat-7 ETM+ band $4(0.77-0.90 \mu m)$, stripes of missing data due to the well-known scan line corrector error. Panels k-t imagery from Landsat-8 OLI band $5(0.85-0.88 \mu \mathrm{m})$. Dates of image acquisition shown in panel title, and dates of drainages (Figure 4) as identified through daily MODIS dynamic thresholding method (Section 2.3) shown in table insert. Landsat-7 and -8 imagery used courtesy of the U.S. Geological Survey. 
https://doi.org/10.5194/tc-2021-184

Preprint. Discussion started: 12 July 2021

(c) Author(s) 2021. CC BY 4.0 License.

(c) (i)

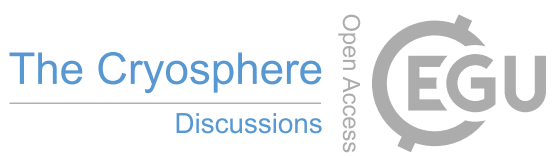

\section{Code availability}

505 An annotated MATLAB script to perform the POD from the stack of ice velocity magnitude rasters, and recreate the results of this study is available at https://doi.org/10.5281/zenodo.4699392.

\section{Data availability}

Data generated and presented in this manuscript is available at https://doi.org/10.5281/zenodo.4699392. All secondary data used in this manuscript is provided from the relevant citation within the reference list.

\section{Author contribution:}

DWA and DWFM conceptualised the study and led the interpretation. DWA led the POD analysis, data synthesis and manuscript writing. JEH provided guidance on the POD analysis. SB and JML performed the MODIS Google Earth Engine processing and advised on the interpretation of supraglacial hydrology. SB performed MAR data analysis. IJN provided guidance on the implications of results for ice dynamics and modelling. All authors contributed to and commented on drafts

515 of the manuscript.

\section{Competing interests:}

The authors declare that they have no conflict of interest.

\section{Acknowledgements}

We thank the authors of the several open datasets used in this study, especially Joughin et al. (2020b), for making their results readily available. We also acknowledge several open-source Python 3 packages used for file management (os, glob) and geospatial data processing (Rasterio, GDAL, NumPy) in this study. To transfer data between NumPy and MATLAB for matrix processing we acknowledge npy-matlab (https://github.com/kwikteam/npy-matlab).

\section{References}

Albidah, A. B., Brevis W., Fedun, V., Ballai, I., Jess, D. B., Stangalini, M., Higham, J., and Verth G.: Proper orthogonal and dynamic mode decomposition of sunspot data, Phil. Trans. R. Soc. A. 379, doi:10.1098/rsta.2020.0181, 2020.

Andrews, L. C., Catania, G. A, Hoffman, M. J., Gulley J. D., Lüthi, M. P., Ryser, C., Hawley, R. L. and Neumann, T. A.: Direct observations of evolving subglacial drainage beneath the Greenland Ice Sheet. Nature, 514, 80-83, doi:10.1038/nature13796, 2014. 
https://doi.org/10.5194/tc-2021-184

Preprint. Discussion started: 12 July 2021

(c) Author(s) 2021. CC BY 4.0 License.

Bevan, S. L., Luckman, A. J., Benn, D. I., Cowton, T., and Todd, J.: Impact of warming shelf waters on ice mélange and terminus retreat at a large SE Greenland glacier, The Cryosphere, 13, 2303-2315, doi:10.5194/tc-13-2303-2019, 2019.

Bian Y., Yue J., Gao W., Li Z., Lu D., Xiang Y., and Chen J.: Analysis of the Spatiotemporal Changes of Ice Sheet Mass and Driving Factors in Greenland, Remote Sens., 11(7), 862, doi:10.3390/rs11070862

Bondzio, J. H., Morlighem, M., Seroussi, H., Kleiner, T., Rückamp, M., Mouginot, J., Moon, T., Larour, E. Y., and Humbert A.: The mechanisms behind Jakobshavn Isbræ's acceleration and mass loss: A 3-D thermomechanical model study, Geophys. Res. Lett., 44, 12, 6252-6260, doi: 10.1002/2017GL073309, 2017.

Brough, S., Carr, J. R., Ross, N., and Lea, J.M.: Exceptional Retreat of Kangerlussuaq Glacier, East Greenland, Between 2016 and 2018, Front. Earth Sci., 7, 123, doi: 10.3389/feart.2019.00123, 2019.

Cassotto, R., Fahnestock, M., Amundson, J. M., Truffer, M. and Joughin, I.: Seasonal and interannual variations in ice melange and its impact on terminus stability, Jakobshavn Isbræ, Greenland, J. Glaciol., 61, 225, 76-88, doi:10.3189/2015JoG13J235, 2015.

Catania, G. A., Stearns, L. A., Moon, T., Enderlin, E., and Jackson, R.H.: Future evolution of Greenland's marine-terminating outlet glaciers, J. Geophys. Res.-Earth, 125, e2018JF004873. doi:10.1029/2018JF004873, 2020.

Chandler, D., Wadham, J., Lis, G., Cowton T., Sole, A., Bartholomew, I., Telling, J., Nienow, P., Bagshaw, E. B., Mair, D., Vinen, S., and Hubbard, A.: Evolution of the subglacial drainage system beneath the Greenland Ice Sheet revealed by tracers, Nature Geosci 6, 195-198, doi:10.1038/ngeo1737, 2013.

Choi, Y., Morlighem, M., Rignot, E. and Wood, M.: Ice dynamics will remain a primary driver of Greenland ice sheet mass loss over the next century. Commun. Earth. Environ. 2, 26, doi:10.1038/s43247-021-00092-z, 2021

Colgan, W., Steffen, K., McLamb, W. S., Abdalati, W., Rajaram, H., Motyka, R., Phillips, T., and Anderson, R.: An increase in crevasse extent, West Greenland: Hydrologic implications, Geophys. Res. Lett., 38, L18502, doi:10.1029/2011GL048491, 2011.

Cooley, S. W., and Christoffersen, P.: Observation bias correction reveals more rapidly draining lakes on the Greenland Ice Sheet. J. Geophys. Res.-Earth, 122, 1867- 1881, doi: 10.1002/2017JF004255, 2017.

Datta, R. T., Tedesco, M., Fettweis, X., Agosta, C., Lhermitte, S., Lenaerts, J. T. M., and Wever, N.: The effect of Foehninduced surface melt on firn evolution over the northeast Antarctic peninsula, Geophys. Res. Lett, 46, 3822- 3831, doi:10.1029/2018GL080845, 2019.

Davison, B. J., Sole, A. J., Cowton, T. R., Lea, J. M., Slater, D. A., Fahrner, D., and Nienow, P. W.: Subglacial drainage evolution modulates seasonal ice flow variability of three tidewater glaciers in southwest Greenland, J. Geophys. Res.Earth, 125, e2019JF005492, doi:10.1029/2019JF005492, 2020.

Davison, B. J., Sole, A. J., Livingstone, S. J., Cowton, T. R., and Nienow, P. W.: The influence of hydrology on the dynamics of the land-terminating sectors of the Greenland Ice Sheet, Front. Earth Sci., 7, 10, doi: 10.3389/feart.2019.00010, 2019.

D'Errico, J.: inpaint_nans (https://www.mathworks.com/matlabcentral/fileexchange/4551-inpaint_nans), MATLAB Central File Exchange. Retrieved Sept 15, 2020. 
https://doi.org/10.5194/tc-2021-184

Preprint. Discussion started: 12 July 2021

(c) Author(s) 2021. CC BY 4.0 License.

Fahnestock, M., Scambos, T., Moon, T., Gardner, A., Haran, T., and Klinger, M.: Rapid large-area mapping of ice flow using Landsat 8, Remote Sens. Environ., 185, 84-94, doi: 10.1016/j.rse.2015.11.023, 2016.

Fahrner, D., Lea, J. M., Brough, S., Mair, D. W. F., and Abermann, J.: Linear response of the Greenland ice sheet's tidewater glacier terminus positions to climate, J. Glaciol., 67, 262, 193-203, doi:10.1017/jog.2021.13, 2021.

Felikson, D., Bartholomaus, T., Catania, G. Korsgaard, N. J., Kjær, K. H., Morlighem, M., Noël, B., van den Broeke, M., Stearns, L. A., Shroyer, E. L., Sutherland, D. A., and Nash, J. D.: Inland thinning on the Greenland ice sheet controlled by outlet glacier geometry, Nature Geosci., 10, 366-369, doi:10.1038/ngeo2934, 2017.

Gorelick, N., Hancher, M., Dixon, M., Ilyushchenko, S., Thau, D. and Moore, R.: Google Earth Engine: Planetary-scale geospatial analysis for everyone, Remote Sens. Environ., 202, 18-27, doi: 10.1016/j.rse.2017.06.031, 2017.

Greene, C. A., Gardner, A. S., and Andrews, L. C.: Detecting seasonal ice dynamics in satellite images, The Cryosphere, 14, 4365-4378, https://doi.org/10.5194/tc-14-4365-2020, 2020.

Higham, J. E., Brevis, W., and Keylock, C. J.: Implications of the selection of a particular modal decomposition technique for the analysis of shallow flows. J. Hydraul. Res., 56(6), 796-805. doi:10.1080/00221686.2017.1419990, 2018.

Higham, J. E., Brevis, W., Keylock, C. J., and Safarzadeh, A.: Using modal decompositions to explain the sudden expansion of the mixing layer in the wake of a groyne in a shallow flow. Adv. Water Resour., 107, 451-459. doi:10.1016/j.advwatres.2017.05.010, 2017.

Higham, J. E., Shahnam, M., and Vaidheeswaran, A.: Using a proper orthogonal decomposition to elucidate features in granular flows. Granul. Matter, 22(4), doi:10.1007/s10035-020-01037-7, 2020.

Hoffman, M., Andrews, L., Price, S., Catania, G. A., Neumann, T. A., Lüthi, M. P., Gulley, J., Ryser, C., Hawley, R. L., and Morris, B. Greenland subglacial drainage evolution regulated by weakly connected regions of the bed. Nat Commun., 7 , 13903, doi:10.1038/ncomms13903, 2016.

Holland, D. M., Thomas, R. H., deYoung, B., Ribergaard, M. H., and Lyberth, B.: Acceleration of Jakobshavn Isbræ triggered by warm subsurface ocean waters, Nat. Geosci., 1, 659-664, doi:10.1038/ngeo316, 2008.

Howat, I. M., Box, J. E., Ahn, Y., Herrington, A., and McFadden, E. M.: Seasonal variability in the dynamics of marineterminating outlet glaciers in Greenland, J. Glaciol., 56, 198, 601-613, doi:10.3189/002214310793146232, 2010.

Iken, A., Röthlisberger, H., Flotron, A. and Haeberli, W.: The uplift of Unteraargletscher at the beginning of the melt season a consequence of water storage at the bed?, J. Glaciol., 29, 101, 28-47, doi:10.3189/S0022143000005128, 1983.

Jolliffe, I., T., and Cadima, J.: Principal component analysis: a review and recent developments, Phil. Trans. R. Soc. A., 374, doi:10.1098/rsta.2015.0202, 2016.

Joughin, I., Shean, D. E., Smith, B. E., and Floricioiu, D.: A decade of variability on Jakobshavn Isbræ: ocean temperatures pace speed through influence on mélange rigidity, The Cryosphere, 14, 211-227, doi:10.5194/tc-14-211-2020, 2020a.

Joughin, I., Howat, I., Smith, B., and T. Scambos, T.: MEaSUREs Greenland Ice Velocity: Selected Glacier Site Velocity Maps from InSAR, Version 3. Subregion W69.10N. Boulder, Colorado USA. NASA National Snow and Ice Data Center Distributed Active Archive Center. http://dx.doi.org/10.5067/YXMJRME5OUNC. [Accessed 3-Sept-2020], 2020b. 
https://doi.org/10.5194/tc-2021-184

Preprint. Discussion started: 12 July 2021

(c) Author(s) 2021. CC BY 4.0 License.

(c) (i)

Joughin, I., Smith, B. E., Howat, I. M., Scambos, T., and Moon, T.: Greenland flow variability from ice-sheet-wide velocity mapping, J. Glaciol., 56, 415-430, 2010.

Joughin, I.: Ice-sheet velocity mapping: A combined interferometric and speckle-tracking approach, Ann. Glaciol., 34, 195201, 2002.

Khazendar, A., Fenty, I. G., Carroll, D., Gardner, A., Lee, C. M., Fukumori, I., Wang, O., Zhang, H., Seroussi, H., Moller, D., Noël, B. P. Y., van den Broeke, M. R., Steven Dinardo, S., and Willis, J.: Interruption of two decades of Jakobshavn Isbrae acceleration and thinning as regional ocean cools, Nat. Geosci. 12, 277-283, doi:10.1038/s41561-019-0329-3, 2019.

King, M. D., Howat, I. M., Candela, S. G., Noh, M. J., Jeong, S., Noël, B. P. Y., van den Broeke, M. R., Wouters, B., and Negrete, A.: Dynamic ice loss from the Greenland Ice Sheet driven by sustained glacier retreat. Commun Earth Environ 1, 1, doi:10.1038/s43247-020-0001-2, 2020.

Lampkin, D. J., Amador, N., Parizek, B. R., Farness, K., and Jezek, K.: Drainage from water-filled crevasses along the margins of Jakobshavn Isbræ: A potential catalyst for catchment expansion, J. Geophys. Res.-Earth, 118, 795- 813, doi:10.1002/jgrf.20039, 2013.

Lemos, A., Shepherd, A., McMillan, M., Hogg, A. E., Hatton, E., and Joughin, I.: Ice velocity of Jakobshavn Isbræ, Petermann Glacier, Nioghalvfjerdsfjorden, and Zachariæ Isstrøm, 2015-2017, from Sentinel 1-a/b SAR imagery, The Cryosphere, 12, 2087-2097, doi:10.5194/tc-12-2087-2018, 2018.

Liang, Y.-L., Colgan, W., Lv, Q., Steffen, K., Abdalati, W., Stroeve, J., Gallaher, D. and Bayou, N.: A decadal investigation of supraglacial lakes in West Greenland using a fully automatic detection and tracking algorithm, Remote Sens. Environ, 123, 127-138, doi:10.1016/j.rse.2012.03.020, 2012.

Lumley, J.L.: The Structure of Inhomogeneous Turbulent Flows. In: Yaglom, A.M. and Tartarsky, V.I., Eds., Atmospheric Turbulence and Radio Wave Propagation, 166-177, 1967.

MacKie, E., Schroeder, D., Zuo, C., Yin, Z., and Caers, J.: Stochastic modeling of subglacial topography exposes uncertainty in water routing at Jakobshavn Glacier. J. Glaciol., 67(261), 75-83, doi:10.1017/jog.2020.84, 2021.

Mair, D., Nienow, P., Sharp, M., Wohlleben, T., and Willis, I.: Influence of subglacial drainage system evolution on glacier surface motion: Haut Glacier d'Arolla, Switzerland, J. Geophys. Res.-Sol Ea, 107(B8), doi: 10.1029/2001JB000514, 2002.

Mair. D., Willis, I., Fischer, U. H., Hubbard, B., Nienow, P., and Hubbard, A.: Hydrological controls on patterns of surface, internal and basal motion during three "spring events": Haut Glacier d'Arolla, Switzerland, J. Glaciol., 49, 167, 555-567, doi:10.3189/172756503781830467, 2003.

Mernild, S. H., Beckerman, A. P., Knudsen, N. T., Hasholt, B., and Yde, J. C.: Statistical EOF analysis of spatiotemporal glacier mass-balance variability: a case study of Mittivakkat Gletscher, SE Greenland, Geografisk Tidsskrift-Danish Journal of Geography, 118:1, 1-16, doi:10.1080/00167223.2017.1386581, 2017.

Moon, T., Joughin, I., Smith, B., van den Broeke, M. R., van de Berg, W. J., Noël, B., and Usher, M.: Distinct patterns of seasonal Greenland glacier velocity, Geophys. Res. Lett., 41, 7209- 7216, doi:10.1002/2014GL061836, 2014. 
https://doi.org/10.5194/tc-2021-184

Preprint. Discussion started: 12 July 2021

(c) Author(s) 2021. CC BY 4.0 License.

Morlighem, M., Williams, C. N., Rignot, E., An, L., Arndt, J. E., Bamber, J. L., Catania, G., Chauché, N., Dowdeswell, J. A., Dorschel, B., Fenty, I., Hogan, K., Howat, I., Hubbard, A., Jakobsson, M., Jordan, T. M., Kjeldsen, K. K., Millan, R., Mayer, L., Mouginot, J., Noël, B. P. Y., O'Cofaigh, C., Palmer, S., Rysgaard, S., Seroussi, H., Siegert, M. J., Slabon, P., Straneo, F., van den Broeke, M. R., Weinrebe, W., Wood, M., and Zinglersen, K. B.: BedMachine v3: Complete bed topography and ocean bathymetry mapping of Greenland from multibeam echo sounding combined with mass conservation, Geophys. Res. Lett., 44, 11,051- 11,061, doi:10.1002/2017GL074954, 2017.

Mouginot, J. and Rignot, E.: Glacier catchments/basins for the Greenland Ice Sheet, Dryad, Dataset, doi:10.7280/D1WT11, 2019.

Mouginot, J., Rignot, R., Bjørk, A. A., van den Broeke, M., Millan, R., Morlighem, M., Noël, B., Scheuchl, B., and Wood, M.: Forty-six years of Greenland Ice Sheet mass balance from 1972 to 2018, P. Natl. Acad. Sci. USA, 116(19), 92399244, doi: 10.1073/pnas.1904242116, 2019.

Navarra, A. and Simoncini, V.: A Guide to Empirical Orthogonal Functions for Climate Data Analysis, Springer Netherlands, doi:10.1007/978-90-481-3702-2, 2010.

Nield, G. A., Whitehouse, P. L., King, M. A., Clarke, P. J., and Bentley, M. J.: Increased ice loading in the Antarctic Peninsula since the $1850 \mathrm{~s}$ and its effect on glacial isostatic adjustment, Geophys. Res. Lett., 39, L17504, doi:10.1029/2012GL052559, 2012.

Nienow, P., Sharp, M. and Willis, I.: Seasonal changes in the morphology of the subglacial drainage system, Haut Glacier d'Arolla, Switzerland. Earth Surf. Process. Landforms, 23: 825-843, 1998.

Pitcher, H.L., Smith, L.C., Gleason, C.J., Miège, C., Ryan, J.C., Hagedorn, B., Van As, D., Chu, W. and Forster, R.: Direct Observation of Winter Meltwater Drainage from the Greenland Ice Sheet. Geophys. Res. Lett., 47 (9), doi:10.1029/2019GL086521

Riel, B., Minchew, B., and Joughin, I.: Observing traveling waves in glaciers with remote sensing: new flexible time series methods and application to Sermeq Kujalleq (Jakobshavn Isbræ), Greenland, The Cryosphere, 15, 407-429, doi:10.5194/tc-15-407-2021, 2021.

Schmid, P. J.: Dynamic mode decomposition of numerical and experimental data, J. Fluid. Mech., 656, 5 - 28, doi:10.1017/S0022112010001217, 2010.

Schwanghart, W. and Scherler, D.: Short Communication: TopoToolbox 2 - MATLAB-based software for topographic analysis and modeling in Earth surface sciences, Earth Surf. Dynam., 2, 1-7, doi:10.5194/esurf-2-1-2014, 2014.

Selmes, N., Murray, T., and James, T. D.: Fast draining lakes on the Greenland Ice Sheet, Geophys. Res. Lett., 38, L15501, doi:10.1029/2011GL047872, 2011.

660 Shreve, R.: Movement of Water in Glaciers, J. Glaciol., 11(62), 205-214. doi:10.3189/S002214300002219X, 1972.

Slater, D. A., Straneo, F., Felikson, D., Little, C. M., Goelzer, H., Fettweis, X., and Holte, J.: Estimating Greenland tidew ater glacier retreat driven by submarine melting, The Cryosphere, 13, 2489-2509, doi:10.5194/tc-13-2489-2019, 2019. 
https://doi.org/10.5194/tc-2021-184

Preprint. Discussion started: 12 July 2021

(c) Author(s) 2021. CC BY 4.0 License.

(c) (1)

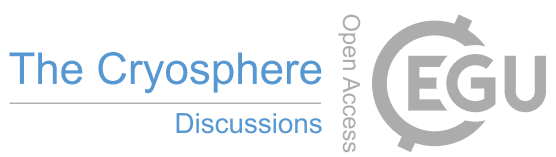

Sole, A. J., Mair, D. W. F., Nienow, P. W., Bartholomew, I. D., King, M. A., Burke, M. J., and Joughin, I.: Seasonal speedup of a Greenland marine-terminating outlet glacier forced by surface melt-induced changes in subglacial hydrology, J. Geophys. Res.-Earth, 116, F03014, doi:10.1029/2010JF001948, 2011.

Straneo, F., Hamilton, G. S., Sutherland, D. A., Stearns, L. A., Davidson, F., Hammill, M. O., Stenson, G. B., Rosing-Asvid, A.: Rapid circulation of warm subtropical waters in a major glacial fjord in East Greenland, Nat. Geosci., 3, 182-186, doi:10.1038/ngeo764, 2008.

Sundal, A. V., Shepherd, A., van den Broeke, M., van Angelen J., Gourmelen, N. and Park, J.: J. Glaciol., 59, 217, 883-892, doi:10.3189/2013JoG13J019, 2013.

Vijay, S., Khan, S. A., Kusk, A., Solgaard, A. M., Moon, T., and Bjørk, A. A.: Resolving seasonal ice velocity of 45 Greenlandic glaciers with very high temporal details, Geophys. Res. Lett., 46, 1485- 1495, doi:10.1029/2018GL081503, 2019.

Weiss, J.: A Tutorial on the Proper Orthogonal Decomposition, AIAA 2019-3333, AIAA Aviation 2019 Forum, doi:10.2514/6.2019-3333, 2019.

Williamson, A. G., Arnold, N. S., Banwell, A. F., and Willis, I. C.: A fully automated supraglacial lake area and volume tracking ("FAST"): development and application using MODIS imagery of West Greenland, Remote Sens. Environ, 196, 113-133, doi:10.1016/j.rse.2017.04.032, 2017. 